\title{
THYROID SWELLING AND IT'S ASSOCIATION WITH THYROID HORMONE STATUS AND BLOOD LIPID PROFILE: A CROSS-SECTIONAL STUDY
}

KEY WORDS:

\section{Dr. Arup Chakraborty*}

MS, ENT, Medical Officer, Deptt. of ENT. *Corresponding Author

\section{Dr. Prabir Kumar}

Saha

\section{Dr. Arpita Das \\ Dr. Bidhan Das}

\author{
MS, ENT, Professor \& HOD ,Deptt. of ENT.
}

MD, Biochemistry, Assistant Professor ,Deptt. of Biochemistry.

Disease of thyroid gland are among the most abundant endocrine disorder in the world second only to diabetes mellitus . Thyroid diseases namely hypothyroidism and hyperthyroidism, constitutes the most common endocrine abnormality in recent years, diagnosed either in subclinical or clinical form. One observational cross sectional study was conducted in the department of ENT, Tripura Medical College \& DR.BRAM Teaching hospital involving 75 nos of subjects having thyroid swellings. Mean value of T3,T4 and TSH was different in cases of euthyroid, hypothyroid, hyperthyroid and subclinical hypothyroid subject. It was of statistically significant. Here P value of T3, T4 \& TSH according to thyroid hormone status were less than $0.05(\alpha \%)$ level of significance. There was statistically difference in average value of T3,T4 \& TSH with different thyroid hormone status at $5 \%$ level of significance. We found that $9.3 \%$ of the study subjects were having altered lipid profile. We found that $62.5 \%$ of hypothyroid subjects were having altered lipid profile . Amongst them, all subclinical hypothyroid subjects were having altered lipid profile. Whereas hyperthyroid subjects were having normal lipid profile. Two (3.07\%) euthyroid cases were having altered lipid profile. We found that mean values of total cholesterol, triglyceride, HDL, LDL and VLDL was different in cases of euthyroid, hypothyroid, hyperthyroid and subclinical hypothyroid subject. It was of statistically significant. Here P value of total cholesterol, triglyceride, HDL, LDL and VLDL according to thyroid hormone status were less than $0.05(\alpha \%)$ level of significance. There was statistically difference in average value of total cholesterol, triglyceride, HDL, LDL and VLDL with thyroid hormone status at 5\% level of significance.

\section{INTRODUCTION-}

Disease of thyroid gland are among the most abundant endocrine disorder in the world second only to diabetes mellitus ${ }^{(1)}$. Thyroid diseases namely hypothyroidism and hyperthyroidism, constitutes the most common endocrine abnormality in recent years, diagnosed either in subclinical or clinical form ${ }^{(2)}$. Genetic, cultural and dietary factors play an important role in determining goiter formation. Multi-nodular goiters as well as solitary thyroid nodules are the commonest form of thyroid swelling ${ }^{(3)}$. Although the most common cause of thyroid swelling in developed communities is immunologic, worldwide iodine deficiency is the commonest cause of thyroid swelling, which holds good in our country as well ${ }^{(4)}$. The incidence of thyroid nodules has increased steadily over the last 30 years. Some of this increase may be due to advances in diagnostic tools, including high-resolution ultrasonography and computed tomography, allowing for greater detection of thyroid nodules, which may not have been detected before ${ }^{(5)}$. The pathogenesis of goiter nodules involves two entirely different processes, which shall be considered separately. The first is accumulation of large strands of connective tissue throughout growing goiters and the second is the replication of normal thyroid follicles ${ }^{(6)}$.

Epidemiological studies have shown that India has the world's highest goiter belt in the Sub-Himalayan region with a prevalence of $29 \%{ }^{(7)}$. According to a survey conducted under the National Goitre Programme during the period from 195770 , the prevalence rate of goiter ranged from $13.2 \%$ in Sibsagar district to $40 \%$ in Gopalpara district of Assam. In India the prevalence of a palpable thyroid nodule in the community is about $12.2 \%{ }^{(8)}$.

Any goitrogenic stimulus, whether TSH , growth promoting immunoglobulin or locally arising growth factors, must be a weak agent acting over long period of time in order to cause simple goiter. Indeed it is only under these conditions that epithelial cell families exceedingly sensitive to growth factors start to replicate and to generate new follicles without other follicular functions being simultaneously stimulated ${ }^{(9)}$. It is quite common that single thyroid adenomas occurring in countries where overall goiter incidence is low ${ }^{(10,11,12)}$. The hormones secreted from the thyroid gland are thyroxin $\mathrm{T} 4$ and tryiodothyronine T3. T3 is active hormone and T4 act as prohormone. Only $20 \%$ of $\mathrm{T} 3$ is secreted from thyroid and rest $80 \%$ comes from $\mathrm{T} 4$ deiodination in periphery organ like liver and kidney ${ }^{(13)}$. Thyroid hormone regulates metabolic rate, body temperature and tissue growth. The thyroid gland is made up of follicles, which are surrounded by a single layer of epithelial cell called follicular cell. Follicle absorbs iodine and stores it in thyroglobulin, a glycoprotein synthesized within thyroid cells. The thyroid hormone synthesis can be summarized in four steps. Firstly active uptake of circulating iodine to cytosol by sodium-iodide symporter, secondly oxidation of iodide by thyroid peroxidase and iodination of tyrosine residues as thyroglobulin molecule, creating mono and diiodotyrosines. Thirdly coupling of iodinated tyrosine residues to form T3 and T4 and fourthly the step of proteolysis due to hydrolysis and releasing the T3 and T4 in cytosol ${ }^{(14)}$.

Thyroid hormones influences all aspects of lipid metabolism includes synthesis, mobilization and degradation. Dyslipidemia is a common metabolic abnormality in patients with thyroid disease, either in the overt or subclinical forms of the disease and constitutes the end result of effect of thyroid hormones in all aspects of lipid metabolism leading to various quantitative and /or qualitative changes of triglycerides, phospholipids, cholesterol and other lipoproteins ${ }^{(15)}$. In thyroid disease, dyslipidemia and the co-existing metabolic abnormalities, in combination with thyroid hormone induced haemodynamic alterations, explain the high risk for cardiovascular disease ${ }^{(16,17,18,19)}$. The prevalence of metabolic syndrome was also higher in subjects with thyroid nodules than in those without ${ }^{(20)}$. Surgical treatments of thyroid swelling are more dealt with in the department of ENT now a days. In this context, present study will be undertaken to find 
out association of thyroid swelling with thyroid hormone status and blood lipid profile status of patients, if any.

\section{REVIEW OF LITERATURE}

Shashi and Sharma ${ }^{(21)}$ conducted one study in Punjab 2015, alteration in lipid metabolism in patients of thyroid dysfunction. It was noteworthy in this study that even a slight alteration in thyroid hormones showed a significant alteration in serum lipids.TSH hormone level was significantly $(\mathrm{p}<0.001)$ lower in overt and subclinical hyperthyroid patients compared with euthyroid group. The total cholesterol level showed a significant $(p<0.01)$ decrease in overt hyperthyroid patients in comparison to euthyroid control.

Juyoung Shin ${ }^{(20)}$ et al during May 2015 in South Korea conducted study to evaluate the relationship between thyroid nodules and metabolic syndrome and its components in apparently healthy Koreans and they found there is positive relationship between components of metabolic syndrome. Of the 1990 subjects included in the study , 38.4\% had thyroid nodules and $12.7 \%$ had metabolic syndrome. Female sex, older age , higher BMI, larger waist circumference, higher $\mathrm{HbAlC}$, lower TSH level and presence of metabolic syndrome were closely related with presence of thyroid nodules.

Melpomeni Peppa et al ${ }^{(22)}$ conducted one study on May 2011 in Greece and found that thyroid hormones regulate the expression of enzymes involved in all steps of lipid metabolism leading to the development of quantitative and qualitative change of lipids in thyroid diseases. Dyslipidemia coexist with other metabolic abnormalities, including hypertension, insulin resistance and oxidative stress, all of them being risk factors for cardiovascular disease.

C.V Rizos et al ${ }^{(23)}$ conducted one study in Greece 2011 and found that thyroid dysfunction should be taken into account when evaluating and treating dyslipidemic patients.

Elizabeth N. Pearce et al ${ }^{(24)}$ conducted study in 2003-06 at Boston University Medical Centre found that total cholesterol and LDL-C were markedly increased when patients were hypothyroid.

Gutch $\mathrm{M}$ et al ${ }^{(25)}$ conducted one study in 2016 and found that serum HDL was significantly lower and LDL, VLDL, Triglyceride levels and total cholesterol were higher in hypothyroid subjects. They concluded that thyroid hormones up-regulate metabolic pathway relevant to resting energy expenditure.

Jung ky et al ${ }^{(26)}$ conducted one study, Association between thyroid functions and lipid profiles, apolipoproteins, and high-density lipoprotein function in 2017 and found that total cholesterol, triglyceride, low-density lipoprotein cholesterol and $a p o B$ levels, and apoA-1/ll ratio were significantly increased in the overt hypothyroid state and recovered to baseline values with levothyroxine replacement.

\section{AIM \& OBJECTIVES -}

1. To find out association of thyroid swelling with thyroid hormone status (T3,T4,TSH) of the study participants.

2. To find out association of thyroid swelling with blood lipid profile of the study participants.

3. To find out association of Thyroid hormone status with blood lipid profile of same patient.

\section{MATERIALS \& METHOD-}

Study Type - Observational study.

Study Design- Cross-sectional.

Study Duration -18 Months ( From 15th November 2018 to 15th May 2020)
Study Area - Department of ENT, TMC \& Dr. BRAM teaching hospital , Hapania , Agartala, West Tripura , PIN-799014.

Study Population - Patients presenting with thyroid swelling to OPD \& IPD , department of ENT .

\section{Inclusion Criteria-}

Any Patients with thyroid swelling attending ENT department of TMC \& DR.BRAM Teaching hospital with age varying from 20 years to 65 years.

\section{Exclusion Criteria-}

I. Age less than 20 years and more than 65 years.

II. Patients with Diabetes Mellitus.

III. Patients with Hypertension.

IV. Patients with carcinoma thyroid and any other carcinoma. V. Pregnancy.

VI. Patients who are taking any kinds of hormonal treatment and Lipid lowering drugs.

Ethical Approval - The study was carried out after taking approval from the ethical committee from the institute.

Sample Size - Patient presented with thyroid swelling and fulfilling my inclusion criteria in the department of ENT, TMC \& Dr.BRAM Teaching Hospital, Hapania and gave consent to this study in the said period was 75 .

Sampling Technique - Patient was selected by Convenience sampling technique.

Study Tools - Pre-designed and pre-tested interview schedule [proforma] was used during clinical examination and investigations .

Data Collection Procedure - Patients attending with thyroid swelling to the OPD and IPD of ENT department , TMC \& Dr.BRAM Teaching Hospital and fulfilling our inclusion \& exclusion criteria was selected for study.

Statistical Analysis - Data collected was entered in Microsoft excel and analyzed by R-software and SPSS .

\section{RESULTS-}

The study was conducted from 15th November 2018 to 15th May 2020 in ENT department of TMC \& DR.BRAM Teaching hospital . There was 75 nos of study subject in the study. The results and observations are tabulated as follows.

\section{Thyroid hormone status}

Here we found that $8 \%$ of cases having low T3 level. There was $2.7 \%$ subjects were having high T3 level. All cases were female.

Table-Distribution of T3_Group according to Sex

\begin{tabular}{|c|c|c|c|c|}
\hline T3_Group & Female & Male & Grand Total & $\%$ \\
\hline Decreased & 6 & 0 & 6 & 8.0 \\
\hline Increased & 2 & 0 & 2 & 2.7 \\
\hline Normal & 49 & 18 & 67 & 89.3 \\
\hline Grand Total & 57 & 18 & 75 & 100 \\
\hline
\end{tabular}

If we consider age group, then we found that age group 20-30 years was having most nos of cases of low T3 level.

Table -Distribution ofT3_Group according to Age-group

\begin{tabular}{|c|c|c|c|c|c|c|c|}
\hline T3_Group & $\mathbf{2 0 - 3 0}$ & $\mathbf{3 1 - 4 0}$ & $\mathbf{4 1 - 5 0}$ & $\mathbf{5 1 - 6 0}$ & $\mathbf{6 1 - 6 5}$ & $\begin{array}{c}\text { Grand } \\
\text { Total }\end{array}$ & $\mathbf{\%}$ \\
\hline Decreased & 3 & 1 & 1 & 0 & 1 & 6 & 8.0 \\
\hline Increased & 1 & 0 & 0 & 1 & 0 & 2 & 2.7 \\
\hline Normal & 20 & 21 & 16 & 10 & 0 & 67 & 89.3 \\
\hline Grand Total & $\mathbf{2 4}$ & $\mathbf{2 2}$ & $\mathbf{1 7}$ & $\mathbf{1 1}$ & $\mathbf{1}$ & $\mathbf{7 5}$ & $\mathbf{1 0 0 . 0}$ \\
\hline
\end{tabular}

We also found that $8 \%$ of cases having low T4 level. There was $2.7 \%$ subjects were having high T4 level. All cases were female. 
Table-Distribution of T4_Group according to Sex

\begin{tabular}{|c|c|c|c|c|}
\hline T4_Group & Female & Male & Grand Total & $\%$ \\
\hline Decreased & 6 & 0 & 6 & 8.0 \\
\hline Increased & 2 & 0 & 2 & 2.7 \\
\hline Normal & 49 & 18 & 67 & 89.3 \\
\hline Grand Total & 57 & 18 & 75 & 100 \\
\hline
\end{tabular}

We found that $\mathrm{T} 4$ was low in 6 nos of cases . Out of that $50 \%$ cases was from $20-30$ years group.

\section{Table -Distribution of T4_Group according to Age-group}

\begin{tabular}{|l|c|c|c|c|c|c|c|}
\hline T4_Group & $20-30$ & $31-40$ & $41-50$ & $51-60$ & $61-65$ & Grand Total & $\%$ \\
\hline
\end{tabular}

\begin{tabular}{|c|c|c|c|c|c|c|c|}
\hline Decreased & 3 & 1 & 1 & 0 & 1 & 6 & 8.0 \\
\hline Increased & 1 & 0 & 0 & 1 & 0 & 2 & 2.7 \\
\hline Normal & 20 & 21 & 16 & 10 & 0 & 67 & 89.3 \\
\hline Grand Total & 24 & 22 & 17 & 11 & 1 & 75 & 100 \\
\hline
\end{tabular}

We also found that $10.7 \%$ of cases having increased TSH level . There was $2.7 \%$ subjects were having low TSH level. Only one male subject was having increased TSH level.

\section{Table -Distribution of TSH_Group according to Sex}

\begin{tabular}{|c|c|c|c|c|}
\hline TSH_Group & Female & Male & Grand Total & $\%$ \\
\hline Decreased & 2 & 0 & 2 & 2.7 \\
\hline Increased & 7 & 1 & 8 & 10.7 \\
\hline Normal & 48 & 17 & 65 & 86.7 \\
\hline Grand Total & 57 & 18 & 75 & 100.0 \\
\hline
\end{tabular}

If we consider age group , then we found that age group 20-30 years was having most nos of cases of high TSH level.

Table-Distribution of TSH_Group according to Age-group \begin{tabular}{|l|l|l|l|l|l|l|l|}
\hline TSH_Group $20-30$ & $31-40$ & $41-50$ & $51-60$ & $61-65$ & Grand & $\%$ \\
\hline
\end{tabular}

\begin{tabular}{|c|c|c|c|c|c|c|c|}
\hline TSH_Group & $20-30$ & $31-40$ & $41-50$ & $51-60$ & $61-65$ & $\begin{array}{c}\text { Grand } \\
\text { Total }\end{array}$ & $\%$ \\
\hline Decreased & 1 & 0 & 0 & 1 & 0 & 2 & 2.7 \\
\hline Increased & 3 & 1 & 2 & 1 & 1 & 8 & 10.7 \\
\hline Normal & 20 & 21 & 15 & 9 & 0 & 65 & 86.7 \\
\hline Grand Total & 24 & 22 & 17 & 11 & 1 & 75 & 100.0 \\
\hline
\end{tabular}

If we correlate the thyroid profile findings and classify the subject according to thyroid hormone status , we found that 6 nos cases were hypothyroid and 2 nos cases were hyperthyroid. All cases were female subjects. We found two patients having subclinical hypothyroidism. One each from male and female group. We observed that $86.7 \%$ subjects were euthyroid. $10.7 \%$ cases were hypothyroid and out of this $2.7 \%$ were subclinical hypothyroid.

Table -Distribution of Thyroid Hormone status according to Sex

\begin{tabular}{|c|c|c|c|c|}
\hline Thyroid Hormone status & Female & Male & Grand Total & $\%$ \\
\hline Euthyroid & 48 & 17 & 65 & 86.7 \\
\hline Hyperthyroid & 2 & 0 & 2 & 2.7 \\
\hline Hypothyroid & 6 & 0 & 6 & 8.0 \\
\hline Subclinical Hypothyroid & 1 & 1 & 2 & 2.7 \\
\hline Grand Total & 57 & 18 & 75 & 100 \\
\hline
\end{tabular}

Thyroid hormone status according to sex - Female $=$ Male

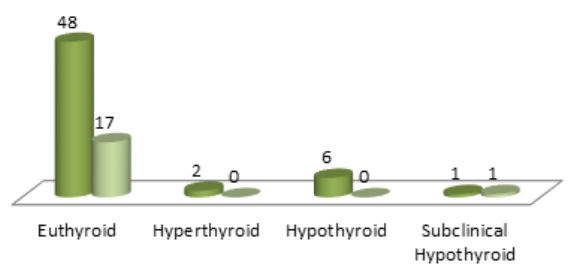

Fig. - Bardiagram of Thyroid hormone status according to sex.

We found maximum hypothyroid cases were in $20-30$ years age group.
Table -Distribution of Thyroid Hormone status according to Age-group

\begin{tabular}{|c|c|c|c|c|c|c|}
\hline $\begin{array}{c}\text { Thyroid Hormone } \\
\text { status }\end{array}$ & $\mathbf{2 0 - 3 0}$ & $\mathbf{3 1 - 4 0}$ & $\begin{array}{c}\mathbf{4 1 -} \\
\mathbf{5 0}\end{array}$ & $\begin{array}{c}\mathbf{5 1 -} \\
\mathbf{6 0}\end{array}$ & $\begin{array}{c}\mathbf{6 1 -} \\
\mathbf{6 5}\end{array}$ & $\begin{array}{c}\text { Grand } \\
\text { Total }\end{array}$ \\
\hline Euthyroid & 20 & 21 & 15 & 9 & 0 & 65 \\
\hline Hyperthyroid & 1 & 0 & 0 & 1 & 0 & 2 \\
\hline Hypothyroid & 3 & 1 & 1 & 0 & 1 & 6 \\
\hline Subclinical Hypothyroid & 0 & 0 & 1 & 1 & 0 & 2 \\
\hline Grand Total & $\mathbf{2 4}$ & $\mathbf{2 2}$ & $\mathbf{1 7}$ & $\mathbf{1 1}$ & $\mathbf{1}$ & $\mathbf{7 5}$ \\
\hline
\end{tabular}

\section{Lipid profile distribution}

We found that 5 nos cases were having increased level of cholesterol. $60 \%$ cases were female subjects.

Table-Distribution of Cholesterol Level according to Sex

\begin{tabular}{|c|c|c|c|c|}
\hline Cholesterol Level & Female & Male & Grand Total & $\%$ \\
\hline Increased & 3 & 2 & 5 & 6.7 \\
\hline Normal & 54 & 16 & 70 & 93.3 \\
\hline Grand Total & $\mathbf{5 7}$ & $\mathbf{1 8}$ & $\mathbf{7 5}$ & $\mathbf{1 0 0}$ \\
\hline
\end{tabular}

We found that 6 nos cases were having increased level of triglyceride. Out of 6 cases 4 nos cases were female subjects.

Table -Distribution of Triglyceride Level according to Sex

\begin{tabular}{|c|c|c|c|c|}
\hline Triglyceride Level & Female & Male & Grand Total & $\%$ \\
\hline Increased & 4 & 2 & 6 & 8 \\
\hline Normal & 53 & 16 & 69 & 92 \\
\hline Grand Total & 57 & 18 & 75 & 100 \\
\hline
\end{tabular}

We found that $9.3 \%$ of the study subjects were having altered lipid profile.

Table -Distribution of Lipid Profile Status according to Sex

\begin{tabular}{|c|c|c|c|c|}
\hline Lipid Profile & Female & Male & Grand Total & $\%$ \\
\hline Altered & 4 & 3 & 7 & 9.3 \\
\hline Normal & 53 & 15 & 68 & 90.7 \\
\hline Grand Total & 57 & 18 & 75 & 100 \\
\hline
\end{tabular}

Bardiagram of lipid profile distribution according to sex

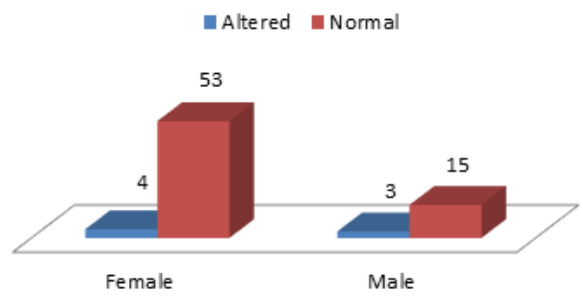

Fig. - Bardiagram of Distribution of lipid profile status according to sex.

We further correlate the lipd profile findings with subjects having altered thyroid hormone status. We found that $62.5 \%$ of hypothyroid subjects were having altered lipid profile. Amongst them, all subclinical hypothyroid subjects were having altered lipid profile. Whereas hyperthyroid subjects were having normal lipid profile. Two (3.07\%) euthyroid cases were having altered lipid profile.

Table -Distribution of Lipid Profile Status according to Thyroid Hormone status

\begin{tabular}{|c|c|c|c|}
\hline Thyroid Hormone Status & $\begin{array}{c}\text { Normal } \\
\text { Lipid Profile }\end{array}$ & $\begin{array}{c}\text { Altered } \\
\text { Lipid Profile }\end{array}$ & Total \\
\hline Hypothyroid & 3 & 3 & 6 \\
\hline Hyperthyroid & 2 & 0 & 2 \\
\hline Subclinical hypothyroid & 0 & 2 & 2 \\
\hline Grand Total & $\mathbf{5}$ & $\mathbf{5}$ & $\mathbf{1 0}$ \\
\hline
\end{tabular}

DISCUSSION- 
The present study was conducted to know the thyroid hormone status and lipid profile of the subjects having thyroid swellings. Also we try to find out any association between hormone status and lipid profile of the study subjects.

\section{Thyroid hormone status-}

Here we found that $8 \%$ of cases having low T3 level. There was $2.7 \%$ subjects were having high T3 level. All cases were female.

If we correlate the thyroid profile findings and classify the subject according to thyroid hormone status, we found that 6 nos cases were hypothyroid and 2 nos cases were hyperthyroid. All cases were female subjects. We found two patients having subclinical hypothyroidism. One each from male and female group.

Keshri et al. ${ }^{(27)}$ in their study observed 3\% patients had TFT suggestive of hyperthyroidism and $2 \%$ hypothyroidism.

Sirish Chandanwalw et $\mathrm{al}^{(28)}$ conducted one study and found that $(78 \%)$ patients were euthyroid, $18(12 \%)$ patients had hyperthyroidism and $15(10 \%)$ patients had hypothyroidism. Here $\mathrm{P}$ value of T3, T4 \& TSH according to size of thyroid swelling were greater than $0.05(\alpha \%)$ level of significance. There was no statistically difference in average value of $\mathrm{T} 3, \mathrm{~T} 4$ \& TSH with size of thyroid swelling at $5 \%$ level of significance.

Table - Distribution of T3,T4 \& TSH according to Size of Thyroid Swelling :-

\begin{tabular}{|c|c|c|c|c|c|c|c|}
\hline $\begin{array}{c}\text { Thyroid } \\
\text { Profile }\end{array}$ & $\begin{array}{c}\text { Size of } \\
\text { Thyroid } \\
\text { Swelling : G1 }\end{array}$ & \multicolumn{2}{|c|}{$\begin{array}{c}\text { Size of } \\
\text { Thyroid } \\
\text { Swelling : G2 }\end{array}$} & \multicolumn{2}{|c|}{$\begin{array}{c}\text { Statistical } \\
\text { Significance }\end{array}$} & Remarks \\
\cline { 2 - 7 } & Mean & SD & Mean & SD & $\begin{array}{c}\text { t - } \\
\text { Value }\end{array}$ & $\begin{array}{c}\text { P- } \\
\text { Value }\end{array}$ & \\
\hline T3 & 1.08 & 0.28 & 1.23 & 0.34 & -0.463 & 0.65 & $\begin{array}{c}\text { Not } \\
\text { significant }\end{array}$ \\
\hline T4 & 8.19 & 1.85 & 8.74 & 2.30 & -1.43 & 0.18 & $\begin{array}{c}\text { Not } \\
\text { significant }\end{array}$ \\
\hline TSH & 3.84 & 2.38 & 4.27 & 3.84 & -0.816 & 0.431 & $\begin{array}{c}\text { Not } \\
\text { significant }\end{array}$ \\
\hline
\end{tabular}

But the mean value of T3,T4 and TSH was different in cases of euthyroid, hypothyroid , hyperthyroid and subclinical hypothyroid subject. It was of statistically significant. Here P value of T3, T4 \& TSH according to thyroid hormone status were less than $0.05(\alpha \%)$ level of significance. There was statistically difference in average value of T3, T4 \& TSH with different thyroid hormone status at $5 \%$ level of significance.

Table - Distribution of T3,T4 \& TSH according to Thyroid Impression :-

\begin{tabular}{|c|c|c|c|c|c|c|c|c|c|c|c|}
\hline \multirow[t]{2}{*}{\begin{tabular}{|l|}
$\begin{array}{l}\text { Thyroid } \\
\text { Profile }\end{array}$ \\
\end{tabular}} & \multicolumn{2}{|c|}{ Euthyroid } & \multicolumn{2}{|c|}{ Hypothyroid } & \multicolumn{2}{|c|}{ Hyperthyroid } & \multicolumn{2}{|c|}{ S-Hypothyroid } & \multicolumn{2}{|c|}{$\begin{array}{c}\text { Statistical } \\
\text { Significance }\end{array}$} & \multirow[t]{2}{*}{ Remarks } \\
\hline & Mean & SD & Mean & SD & Mean & SD & Mean & SD & F -Value & P-Value & \\
\hline T3 & 1.24 & 0.17 & 0.44 & 0.23 & 2.33 & 0 & 1.35 & 0.01 & 50.07 & $<0.001$ & Significant \\
\hline T4 & 8.9 & 1.15 & 3.3 & 1.78 & 15.96 & 2.16 & 9.01 & 2.87 & 41.87 & $<0.001$ & Significant \\
\hline TSH & 3.28 & 0.78 & 14.97 & 7.08 & 0.22 & 0.03 & 7.2 & 0.82 & 55.87 & $<0.001$ & Significant \\
\hline
\end{tabular}

\section{Lipid profile distribution-}

We found that 5 nos cases were having increased level of cholesterol. $60 \%$ cases were female subjects. We found that 5 nos cases were having increased level of cholesterol. $60 \%$ cases were female subjects.We found that 6 nos cases were having increased level of triglyceride. Out of 6 cases 4 nos cases were female subjects.

We found that $9.3 \%$ of the study subjects were having altered lipid profile.

We further correlate the lipd profile findings with subjects having altered thyroid hormone status. We found that $62.5 \%$ of hypothyroid subjects were having altered lipid profile. Amongst them, all subclinical hypothyroid subjects were having altered lipid profile. Whereas hyperthyroid subjects were having normal lipid profile. Two (3.07\%) euthyroid cases were having altered lipid profile
Here $P$ value of total cholesterol, triglyceride, HDL, LDL and VLDL according to size of thyroid swelling were greater than $0.05(\alpha \%)$ level of significance. There was no statistically difference in average value of total cholesterol, triglyceride, HDL, LDL and VLDL with size of thyroid swelling at $5 \%$ level of significance.

We found that mean values of total cholesterol, triglyceride, HDL, LDL and VLDL was different in cases of euthyroid, hypothyroid, hyperthyroid and subclinical hypothyroid subject. It was of statistically significant. Here P value of total cholesterol, triglyceride, HDL, LDL and VLDL according to thyroid hormone status were less than $0.05(\alpha \%)$ level of significance. There was statistically difference in average value of total cholesterol, triglyceride, HDL, LDL and VLDL with thyroid hormone status at $5 \%$ level of significance.

Table - Distribution of Total Cholesterol, Triglyceride ,HDL,LDL \&VLDL according to Thyroid Impression :-

\begin{tabular}{|c|c|c|c|c|c|c|c|c|c|c|c|}
\hline \multirow[t]{2}{*}{ Lipid Profile } & \multicolumn{2}{|c|}{ Euthyroid } & \multicolumn{2}{|c|}{ Hypothyroid } & \multicolumn{2}{|c|}{ Hyperthyroid } & \multicolumn{2}{|c|}{ S-Hypothyroid } & \multicolumn{2}{|c|}{$\begin{array}{c}\text { Statistical } \\
\text { Significance }\end{array}$} & \multirow[t]{2}{*}{ Remarks } \\
\hline & Mean & SD & Mean & SD & Mean & SD & Mean & SD & F -Value & P-Value & \\
\hline Total Cholesterol & 167.57 & 20.6 & 224.4 & 51.06 & 168 & 5.66 & 217 & 24.04 & 8.723 & $<0.001$ & Significant \\
\hline Triglyceride & 141.63 & 27.17 & 224 & 31.59 & 172 & 8.49 & 229 & 12.73 & 15.43 & $<0.001$ & Significant \\
\hline HDL & 48.26 & 6.34 & 38 & 5.1 & 55 & 4.24 & 36.5 & 3.54 & 5.72 & $<0.001$ & Significant \\
\hline LDL & 97.52 & 16.46 & 135.6 & 39.43 & 94 & 5.66 & 135.5 & 7.78 & 6.86 & $<0.001$ & Significant \\
\hline VLDL & 28.33 & 5.43 & 44.8 & 6.32 & 34.4 & 1.70 & 45.8 & 2.55 & 15.43 & $<0.001$ & Significant \\
\hline
\end{tabular}

Gutch $\mathrm{M}$ et al ${ }^{(25)}$ conducted one study in 2016 and found that serum HDL was significantly lower and LDL, VLDL, Triglyceride levels and total cholesterol were higher in hypothyroid subjects. They concluded that thyroid hormones up-regulate metabolic pathway relevant to resting energy expenditure.

Jung ky et al ${ }^{(26)}$ conducted one study, Association between thyroid functions and lipid profiles, apolipoproteins, and high-density lipoprotein function in 2017 and found that total cholesterol , triglyceride, low-density lipoprotein cholesterol and $a p \circ B$ levels, and apoA-1/ll ratio were significantly increased in the overt hypothyroid state and recovered to baseline values with levothyroxine replacementxpenditure.

\section{CONCLUSION-}

1. 75 nos thyroid swelling case attended in ENT department, Tripura Medical college \& Dr.BRAM Teaching Hospital was mostly female (76\%) and common age group presented was 20 to 40 years(61.3\%). 
2. Thyroid hormone status was mostly euthyroid $(86.6 \%)$, although $10.7 \%$ cases were hypothyroid and $2.7 \%$ cases were hyperthyroid.

3. We found that $9.3 \%$ of the study subjects were having altered lipid profile. Amongst all hypothyroid (8 nos) in the series, $62.5 \%$ had altered lipid profile. Out of eight cases, two cases were subclinical hypothyroid and all subclinical hypothyroid cases had altered lipid profile. It highlights the significance of thyroid function test as well as lipid profile of thyroid swelling patients before management.

\section{REFERENCES-}

1. Heuck CC, Kallner A, Kanagasabapathy AS ,Riesen W. Diagnosis and monitoring of the disease of thyroid. World Health Organisation 2000 ; $8-9$ : 120.

2. Hollowell J.G., Staching N.W, Flanders W.D. Serum TSH , T4 and thyroid antibodies in the united states population (1988- 1994$)$ : National Health and Nutrition Examination Survey (NHANES III). Journal of clinical Endocrinology and Metabolism 2002;87(2):489-499.

3. Townsend Jr. et al.W.B.Saunders Company 2004:947-83.

4. Krukwski Zymum H. The Thyroid and Thyroglossal Duct . Chapter 44, Russel RCG et al ; Bailey and Love's Short Practice of Surgery, $24^{\text {th }}$ edition, Nick Dounton London UK. 2004 :776-804

5. Davies L, Welch HG . Increasing incidence of thyroid cancer in united states by demographic and tumor characteristics 1980-2005. Cancer Epidermal Biomarkers prev $2009 ; 18: 784-791$.

6. Ramelli F, Studer H and Bruggisser D . Pathogenesis of Thyroid Nodules in Multinodular Goiter. The American Journal of Pathology 1982 ; $109: 215-223$.

7. W.H.O.Report of a seminar on goiter control.New Delhi,WHO;Searo:1967.

8. Usha Menon V, Sundaram KR, Unnikrishnan AG, Jayakumar RV, NairV, Kumar H. High prevalence of undetected thyroid disorders in an iodine sufficient adult south Indian population.J Indian Med Assoc 2009;107:72-7.

9. Peter HJ, Studer H, Foster R. The pathogenesis of "hot" and "cold" follicles in multinodular goiters.J clin endocrinal Metab 1982;55(5) : 941-946.

10. Correa P. Pathology of endemic goiter, Endemic Goiter and Endemic cretinism .Edited by JB Stanburg, BS Hetzel .New York, JohnWiley and sons, $1980: 303-332$

11. De Quervain F, Wegelin C. Der endemische Kretinismus ,Pathologie and Klinik in Einzeldarstellungen, Vol 4 . Edited by L Aschoff, H Eppinger , C Sternberg, KFWenckebach. Berlin, Springer-Verlag, 1936: 1-206.

12. Clements FW. Health significance of endemic goiter and related conditions. Endemic Goiter, Geneva;World Health Organization 1960:235-260.

13. Braverman LE. The physiology and pathophysiology of iodine and thyroid. Thyroid 2001;11:405.

14. Triggiani V, Tafaro E, Giagulli VA, Sabba C , Resta F, Li cchelli B et al . Role of iodine, selenium and oyher micronutrients in thyroid function and disorder. Endocr Metab Immune Disorder Drug Targets 2009; 9:277-94

15. Zhu X and Cheng SY. New insights into regulation of lipid metabolism by thyroid hormones. Current opinion in Endocrinology, Diabetes and Obesity 2010;17(5): :408-413.

16. Biondi B , Klein I. Hypothyroidism as a risk factor for cardiovascular disease. Endocrine 2004;24 (1) : 1-13.

17. Biondi B, Kahaly GJ. Cardiovascular involvement in patients with different causes of hyperthyroidism. Nature reviews Endocrinology $2010 ; 6$ (8) : 431443.

18. Klein I, Ojamaa K. Thyroid hormone and cardiovascular system. The New England Journal of Medicine 2001;344 (7) :501-509.

19. Fazio $S$, Palmieri EA , Lombardi G , B Biondi. Effect of thyroid hormone on the cardiovascular system. Recent Progress in Hormone Research 2004; (59) :3150.

20. J Shin J, Kim M, Yoon K ,Kang M , Cha B, Lim D. Relationship between metabolic syndrome and thyroid nodules in healthy Koreans. Korean J Intern Med 2016;31:98-105.

21. Shashi A, Sharma N. Alteration in lipid metabolism in patients of thyroid hyperfunction. International Journal of Basic and Applied Medical Sciences $2015 ; 5$ (1):75-85.

22. Peppa M, Betsi G, Dimitriadis G. Lipid abnormalities and cardiovascular risk in patient with overt and subclinical thyroid disease. Journal of Lipids 2011; 2011:575840.

23. Rizos CV, Elisaf MS, Liberopoulos EN. Effects of Thyroid Dysfunction On Lipid Profile.The Opencardiovascular Medicine Journal 2011 ;5:76-84.

24. Elizabeth N P, W.F.Wilson P, Yang Q, Ramachandran S , Lewis E. Thyroid function and lipid subparticle sizes in patients with short-term hypothyroidism and a population-based cohort. The journal of clinical endocrinology and metabolism 2008; 93 (3):888-894.

25. Gutch M, Rungta S, Kumar S, Agarwal A, Bhattacharya A, Mohd Razi Sd. Thyroid functions and serum lipid profile in metabolic syndrome. Biomedical Journal 2017;40: 147-153.

26. Jung KY, Ahn HY, Han SK. Association between thyroid functions and lipid profiles, apolipoproteins, and high-density lipoprotein function. Journal clin lipidol 2017;11(6): 1347-1353.

27. Keshri SP. Clinico-Pathological Study of Solitary Thyroid Nodule with Special Reference to Fine Needle Aspiration Cytology.IJSR. 2017;6(2):789 94.

28. Chandanwale $S$ et al . Clinicopathological correlation of thyroid nodules. Int $J$ Pharm Biomed Sci 3(3):97-102. 